\title{
Endogenous GABA Attenuates CNS White Matter Dysfunction Following Anoxia
}

\author{
Robert Fern, ${ }^{1,2}$ Stephen G. Waxman, ${ }^{1,2}$ and Bruce R. Ransom ${ }^{1}$ \\ 'Department of Neurology, Yale University School of Medicine, New Haven, Connecticut 06510 and ${ }^{2}$ Neuroscience \\ Research Center, Department of Veterans Affairs Medical Center, West Haven, Connecticut 16516
}

We studied the effects of GABA on anoxia-induced injury in CNS white matter using optic nerves exposed to $60 \mathrm{~min}$ of anoxia. Injury was assessed by recording pre- and postanoxic compound action potentials (CAPs). GABA (1 $\mu \mathrm{m})$ significantly increased postanoxic CAP recovery when applied $60 \mathrm{~min}$ prior to anoxia. This effect was bicuculline (100 $\mu \mathrm{M})$ insensitive, mimicked by baclofen $(1 \mu \mathrm{M})$, blocked by GABA-B antagonists, and not mimicked by selective GABA-A agonists. GABA therefore acted at GABA-B receptors. High concentrations of GABA and baclofen did not influence recovery, possibly indicating GABA-B receptor desensitization at high agonist concentrations.

Pertussis toxin (PTX) treatment reduced postanoxic CAP recovery in the presence of $1 \mu \mathrm{M}$ GABA to control levels, indicating the recruitment of a G-protein-linked intracellular pathway. Protein kinase C (PKC) activation with 12-myristate 13-acetate (PMA) mimicked the effects of GABA. Inhibition of PKC with 1-(5-isoquinolinesulfonyl)-2-methylpiperazine dihydrochloride $(\mathrm{H} 7)$ or staurosporine reduced postanoxic recovery in the presence of GABA to lower levels than under control conditions, confirming the involvement of $P K C$ in the protective effect of GABA and indicating that this GABA-B receptor/G-protein/PKC protective pathway might be active under control conditions. This was confirmed by the observation that GABA-B receptor blockade, in the absence of exogenous GABA, significantly reduced postanoxia recovery. Thus, activation of the protective mechanism under control conditions is due to endogenous GABA release. Increasing the level of endogenous extracellular GABA by blocking GABA uptake with $1 \mathrm{~mm}$ nipecotic acid also protected against anoxia. We propose a model where release of GABA in white matter helps to limit nerve fiber injury during anoxia via recruitment of a G-protein/PKC pathway with subsequent phosphorylation of an unknown target protein.

[Key words: axon, GABA, GABA-B receptors, glia, G-protein, protein kinase $C$, nerve fiber]

The nerve fiber tracts of the CNS contain GABA (Balcom et al., 1975; Van De Hayden et al., 1979; Anden et al., 1987), GABA receptors (Bowery et al., 1987; Chu et al., 1990), and a

Received May 5, 1994; revised June 24, 1994; accepted July 6, 1994.

This work was supported in part by grants from the NINDS (B.R.R.) and the Medical Research Service, Department of Veterans Affairs (S.G.W.). R.F. was supported in part by a fellowship from the Blinded Veterans Association. We thank Dr. H. Sontheimer for advice during the course of these experiments.

Correspondence should be addressed to Robert Fern, Ph.D., 703 LCI, Department of Neurology, Yale University School of Medicine, New Haven, CT O6510. Copyright (C) 1995 Society for Neuroscience 0270-6474/95/150699-10\$05.00/0 high-affinity GABA uptake mechanism (Bull and Blomqvist, 1991). Although the function of GABA in mature CNS white matter is unknown, significant increases in extracellular GABA concentration occur during white matter ischemia (Shimada et al., 1993), and in post-mortem isolated white matter (Anden et al., 1987). Total brain GABA also increases significantly during anoxia (Nilsson and Lutz, 1991). These observations are consistent with a role for GABA in CNS white matter during pathological conditions.

White matter contains no presynaptic terminals and release of neurotransmitters within white matter cannot be synaptic in nature. GABA, however, is found within both the axons and glia which make up white matter (Bull and Blomqvist, 1991; Davanger et al., 1991; Lake, 1992). Conditions are ideal for the release of this GABA during anoxia and ischemia, which favor reverse operation of sodium-dependent GABA uptake (Carvalho et al., 1991; Ransom et al., 1992; Atwell et al., 1993). To examine the possibility that GABA may be involved in the pathophysiology of white matter anoxia, we have employed a model CNS white matter system, the isolated rat optic nerve. Our results indicate that GABA plays a protective role in white matter during anoxia, and we have identified the receptor subtype and intracellular pathway by which GABA acts. Most importantly, it appears that anoxia stimulates release of sufficient endogenous GABA to activate this mechanism in situ, thus providing an intrinsic protective system.

\section{Materials and Methods}

The in vitro rat optic nerve preparation (Davis and Ransom, 1987; Stys et al., 1992) was used to study the role of GABA in anoxia-induced injury of CNS white matter. Female Long-Evans rats 50-70 d old were anesthetized with an $80 \% \mathrm{CO}_{2} / 20 \% \mathrm{O}_{2}$ gas mixture prior to decapitation. The optic nerves were dissected free, placed in a modified interface perfusion chamber (Medical Systems Corp., Greenvale, NY), and incubated for 60-90 min before measurements were initiated. The tissue was maintained at $37^{\circ} \mathrm{C}$, oxygenated in a $95 \% \mathrm{O}_{2} / 5 \% \mathrm{CO}_{2}$ atmosphere, and perfused with artificial cerebrospinal fluid (aCSF) with a pH of 7.45. The aCSF contained (in mM): $\mathrm{Na}^{+}, 153 ; \mathrm{K}^{+}, 3 ; \mathrm{Mg}^{2+}, 2 ; \mathrm{Ca}^{2+}, 2 ; \mathrm{Cl}^{-}$, $133 ; \mathrm{HCO}_{3}{ }^{2-}, 26 ; \mathrm{H}_{2} \mathrm{PO}_{4}{ }^{2-}, 2$; dextrose, 10 .

The recording arrangement was similar to that reported previously (see Stys et al., 1990). In brief, compound action potentials (CAPs) were evoked by a $125 \%$ supramaximal stimulus applied via a suction electrode to the distal nerve end. CAPs were recorded via a second suction electrode from the proximal nerve end employing a method which compensates for instability inherent in the suction electrode technique (Stys et al., 1991). Anoxia was induced by changing to a $5 \% \mathrm{CO}_{2} / 95 \%$ $\mathrm{N}_{2}$ atmosphere, which was maintained for a standard 60 min period. CAP recovery after anoxia was determined by measuring CAP area after $60 \mathrm{~min}$ of reoxygenation, a time after which no further recovery occurs (Stys et al., 1992). Changes in the area under the CAP, calculated by computer, were assumed to correspond to changes in the number of 
A

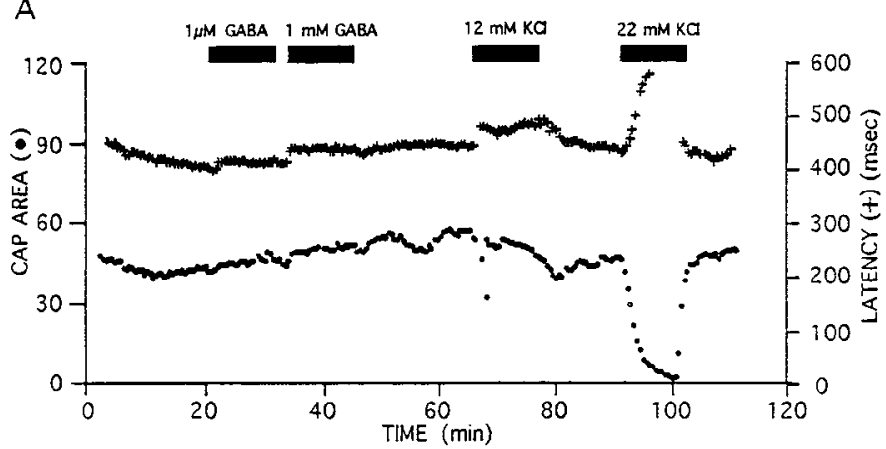

B
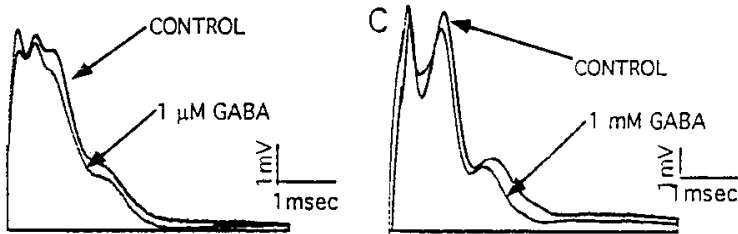

Figure 1. GABA had no consistent action upon the normoxic CAP. $A$, A plot of CAP area ( $\bullet$, arbitrary units) and the latency between stimulus onset and the peak of the first component of the CAP $(+)$. There are no significant changes in these parameters during $10 \mathrm{~min}$ perfusion with either $1 \mu \mathrm{M}$ or $1 \mathrm{mM}$ GABA (indicated by the bars). Twelve and $22 \mathrm{~mm} \mathrm{KCl}$, however, did influence CAP area and latency, providing a positive control. Similar results were found in five optic nerves. $B$ and $C$, Superimposed CAPs recorded prior to (CONTROL) and subsequent to $60 \mathrm{~min}$ of perfusion with $1 \mu \mathrm{M}$ GABA $(B)$ or $1 \mathrm{~mm}$ GABA $(C)$. The small changes in CAP shape and area were not of a consistent nature.

axons capable of conducting action potentials along the optic nerve (Cummins et al., 1979; Stys et al., 1991; Wijesinghe et al., 1991). Results are presented as means \pm SEM. Each experimental protocol employed was accompanied by an independent set of control experiments, typically interspersed between test experiments, and significance was normally tested for by $t$ test. In some cases variations of the same protocol were employed and compared to the same control experiments, in which case significance was tested for by ANOVA (post hoc test).

Experimental protocol. To study the effects of a solution change upon normoxic nerve conduction, comparison was made between the control CAP recorded after $60 \mathrm{~min}$ of aCSF perfusion and the CAP $60 \mathrm{~min}$ after the initiation of perfusion with test solution. The effect of a test solution on CAP recovery from the standard $60 \mathrm{~min}$ anoxic insult was measured by comparing the CAP immediately before anoxia to the CAP recorded $60 \mathrm{~min}$ after the end of anoxia. Only one test solution, at one concentration, was examined in any single optic nerve.

\section{Results}

Sakatani et al. (1992) reported that the application of GABA to the neonatal rat optic nerve results in axonal depolarization, an effect which is much reduced in rats older than $30 \mathrm{~d}$ of age. In the current experiments nerves were taken from 50-70-d-old rats and no significant effect of GABA upon the shape or the area under the normoxic CAP was observed (Fig. 1). The slight changes in the CAP that were observed in the presence of GABA ( $1 \mu \mathrm{M}$ and $1 \mathrm{mM}$ for $60 \mathrm{~min}$ ) were not of a consistent nature or significant in magnitude (Fig. $1 B, C ; n=4$ ).

\section{Low concentrations of $G A B A$ protect against anoxic injury via actions at $G A B A-B$ receptors}

Low concentrations of GABA significantly reduced the development of irreversible dysfunction after a $60 \mathrm{~min}$ period of anoxia in the rat optic nerve. Typical pre- and postanoxic CAPs in Figure $2 A$ illustrate the large reduction in CAP area that results from the standard 60 min anoxic period. Perfusion with

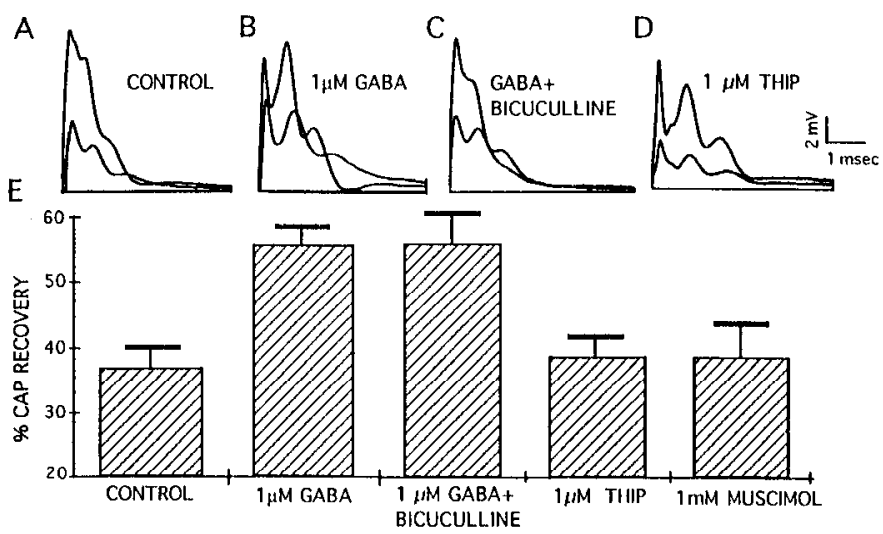

Figure 2. One micromolar GABA acted at a site other than the GABA-A receptor to protect rat optic nerves from anoxia. $A-D$, Superimposed pre- and postanoxic CAPs taken under control conditions $(A)$ and in the presence of various agents applied prior to anoxia $(B-D)$. The larger of each CAP pair is the preanoxic recording and the smaller CAP is the postanoxic recovery. $A$, Under control conditions the mcan postanoxic CAP recovery after anoxia was $36.5 \pm 2.9 \%(n=10) . B$, GABA at $1 \mu \mathrm{M}$ significantly increased recovery to a mean of $55.7 \pm$ $2.5 \%(n=16, p<0.002)$. $C$, The selective GABA-A antagonist bicuculline $(100 \mu \mathrm{M})$, added $10 \mathrm{~min}$ prior to and continually with GABA, did not attenuate the protective effect of $1 \mu \mathrm{M}$ GABA. $D$, The selective GABA-A agonist THIP had no protective effect against anoxia. $E$, Data summary showing that mean recovery in $1 \mu \mathrm{M}$ GABA + bicuculline was $56.1 \pm 4.4 \%(n=12)$, recovery in $1 \mu \mathrm{M}$ THIP was $38.5 \pm 2.9 \%(n$ $=8$ ), and recovery in $1 \mathrm{~mm}$ muscimol (also a selective GABA-A agonist) was $38.6 \pm 4.8 \%(n=7)$.

$1 \mu \mathrm{M}$ GABA significantly increased recovery (Fig. $2 B, E$ ). Mean CAP recovery under control conditions was $36.5 \pm 2.9 \%$ ( $n=$ $10)$; mean CAP recovery in the presence of $1 \mu \mathrm{M}$ GABA was $55.7 \pm 2.5 \%(n=16 ; p<0.002)$.

Previously reported effects of GABA upon nerve fibers have conformed to the pharmacological protile of the GABA-A receptor, being bicuculline sensitive and mimicked by GABA-A agonists (Simmonds, 1983; Liske and Morris, 1989; Sakatani et al., 1991a, 1992). GABA's protective action against anoxic injury was not blocked by $100 \mu \mathrm{M}$ bicuculline, applied $10 \mathrm{~min}$ before and continually with the application of GABA (Fig. 2C,E). Mean CAP recovery in GABA + bicuculline was $56.1 \pm 4.4 \%$ compared to $55.7 \pm 2.5 \%$ in GABA alone. Furthermore, the selective GABA-A agonist 4,5,6,7-tetrahydroisoxazolo[5,4c]pyridine-3-ol hydrochloride (THIP) did not effect the degree of recovery following anoxia. Figure $2, D$ and $E$, shows that postanoxic CAP recovery was not increased by $1 \mu \mathrm{M}$ THIP, while perfusion with $1 \mathrm{mM}$ THIP was also without effect $(n=$ 4). One millimolar muscimol, another selective GABA-A agonist, also did not effect postanoxic CAP recovery. These data are summarized in Figure $2 E$, confirming that GABA-A receptor activation did not act to reduce the extent of anoxic injury.

The protective effect of $1 \mu \mathrm{M}$ GABA was completely abolished by perfusion with $500 \mu \mathrm{M}$ phaclofen, a selective GABA-B antagonist. Recovery was slightly lower during perfusion with GABA and phaclofen than under control conditions (Fig. 3A,C). A perfusion protocol similar to that used with bicuculline was employed, with phaclofen perfusion initiated $10 \mathrm{~min}$ prior to GABA perfusion. The selective GABA-B agonist baclofen (1 $\mu \mathrm{M})$ provided protection from anoxia similar to that found with $1 \mu \mathrm{M}$ GABA, with postanoxic recovery of $53.1 \pm 3.1 \%$ (Fig. $3 B, C)$. 


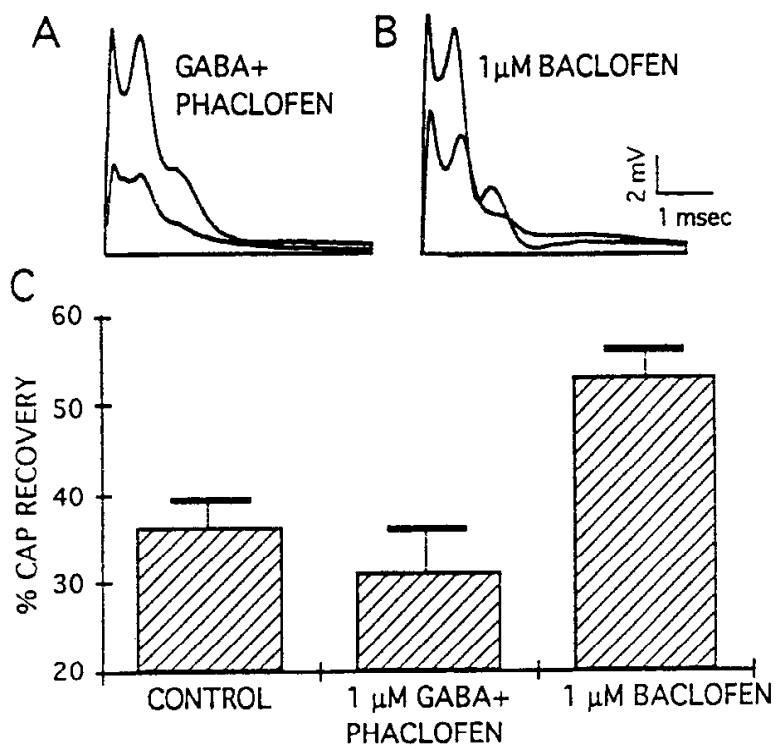

Figure 3. GABA acted via GABA-B receptors. $A$, The selective GABA-B antagonist phaclofen $(500 \mu \mathrm{M})$ blocked the protective effect of 1 $\mu \mathrm{M}$ GABA. $B$, The selective GABA-B agonist baclofen $(1 \mu \mathrm{M})$ mimicked the protective effect of GABA. $C$, Data summary showing that mean postanoxic recovery in the presence of $1 \mu \mathrm{M} \mathrm{GABA}+500 \mu \mathrm{M}$ phaclofen was similar to that found under control conditions $(31.3 \pm 4.7 \%, n=$ 6 compared to $36.5 \pm 2.9 \%, n=12$, respectively), while $1 \mu \mathrm{M}$ baclofen significantly increased recovery $(53.1 \pm 3.1 \%, n=12 ; p<0.005)$.

\section{High concentrations of GABA and baclofen do not protect} against anoxic injury

Optic nerves exposed to increasing GABA concentrations from $10 \mathrm{nM}$ to $1 \mu \mathrm{M}$ showed progressively greater protection against anoxic injury, as shown in the dose-response relationship in Figure $4 C$. However, GABA concentrations higher than $1 \mu \mathrm{M}$ were progressively less effective. Specimen records illustrating the lack of effect of $1 \mathrm{~mm} \mathrm{GABA}$ upon postanoxic CAP recovery are shown in Figure $4 A$ (compare to Fig. 2). That higher concentrations of GABA were less effective at protecting against anoxia may indicate receptor desensitization at high agonist concentrations, over these long application times.

Lee et al. (1993) have reported that GABA may be neurotoxic to spinal cord axons, a toxicity which they suggest is mediated by GABA-A receptors. GABA-A receptor-mediated neurotoxicity at high GABA concentrations could explain the reduced protection found in Figure $4 C$. However, additional experiments indicated that this was not the case. Figure $4 D$ shows the dose-response relationship for the protective effect of baclofen, and demonstrates that the relationship was similar to that found for GABA, having a negative correlation at higher baclofen concentrations. It appeared, therefore, that high GABA-B receptor occupancy was enough to eliminate the protective effects of GABA-B receptor activation. This kind of relationship is typical of receptor desensitization. To confirm that a deleterious effect of GABA-A receptor activation did not underlie the ineffectiveness of high concentrations of GABA, these receptors were blocked by $100 \mu \mathrm{M}$ bicuculline applied $10 \mathrm{~min}$ prior to 1 mM GABA. This failed to unmask any recovery produced by isolated GABA-B receptor activation (mean recovery $=35 \pm$ $4.5 \%, n=4$; Fig. $4 B$ ).

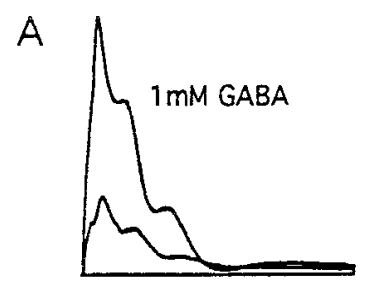

B
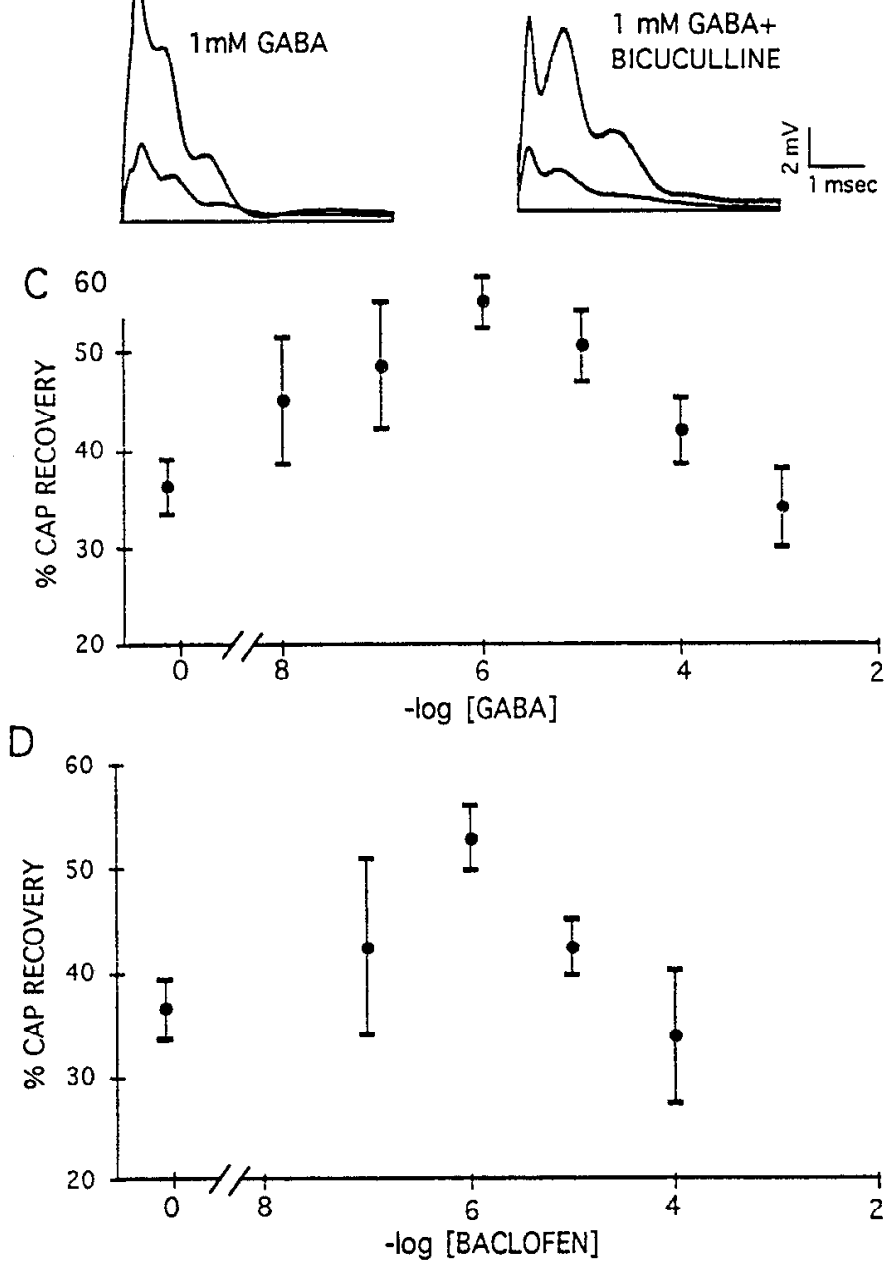

Figure 4. GABA-B receptors appeared to desensitize at high agonist concentrations. $A, \mathrm{GABA}$ at $1 \mathrm{~mm}$ had no protective effect against anoxia (mean CAP recovery $=34.3 \pm 4.1 \%, n=8$ ). $B$. Block of GABA-A receptors with $100 \mathrm{~mm}$ bicuculline did not unmask any protective effect of GABA-B receptor activation with $1 \mathrm{~mm}$ GABA. $C$, Dose-response curve for various GABA concentrations used with the standard anoxia protocol. Increasing GABA concentrations from $10 \mathrm{nM}$ to $1 \mu \mathrm{M}$ produced increasing degrees of recovery. However, concentrations above $1 \mu \mathrm{M}$ had increasingly less effect. Each point is a mean of 6-16 experiments. $D$, Dose-response curve for various baclofen concentrations, showing a similar negative correlation between agonist concentration and protective effect at high concentrations.

\section{Temporal features of GABA-mediated protection}

The above experiments were performed with long GABA perfusion times in an attempt to examine the steady-state effect of GABA application. To examine the evolution of GABA-mediated protection, CAP recovery after anoxia was studied in optic nerves perfused with $1 \mu \mathrm{M}$ GABA beginning 10,30 , and $60 \mathrm{~min}$ before the onset of anoxia (Fig. 5.A-C). Some protection was provided by GABA perfusion initiated $30 \mathrm{~min}$ prior to anoxia, but $10 \mathrm{~min}$ of perfusion had little effect upon postanoxic recovery (Fig. $5 D$ ). This requirement for pre-exposure to GABA was probably not due to slow penetration of the neurotransmitter into the nerve. GABA is a relatively small molecule (MW $=103)$ compared to TTX $(\mathrm{MW}=319)$, and yet TTX has a maximal protective effect against anoxic injury if perfusion is initiated as late as 0 min prior to anoxia (Stys et al., 1992). In 

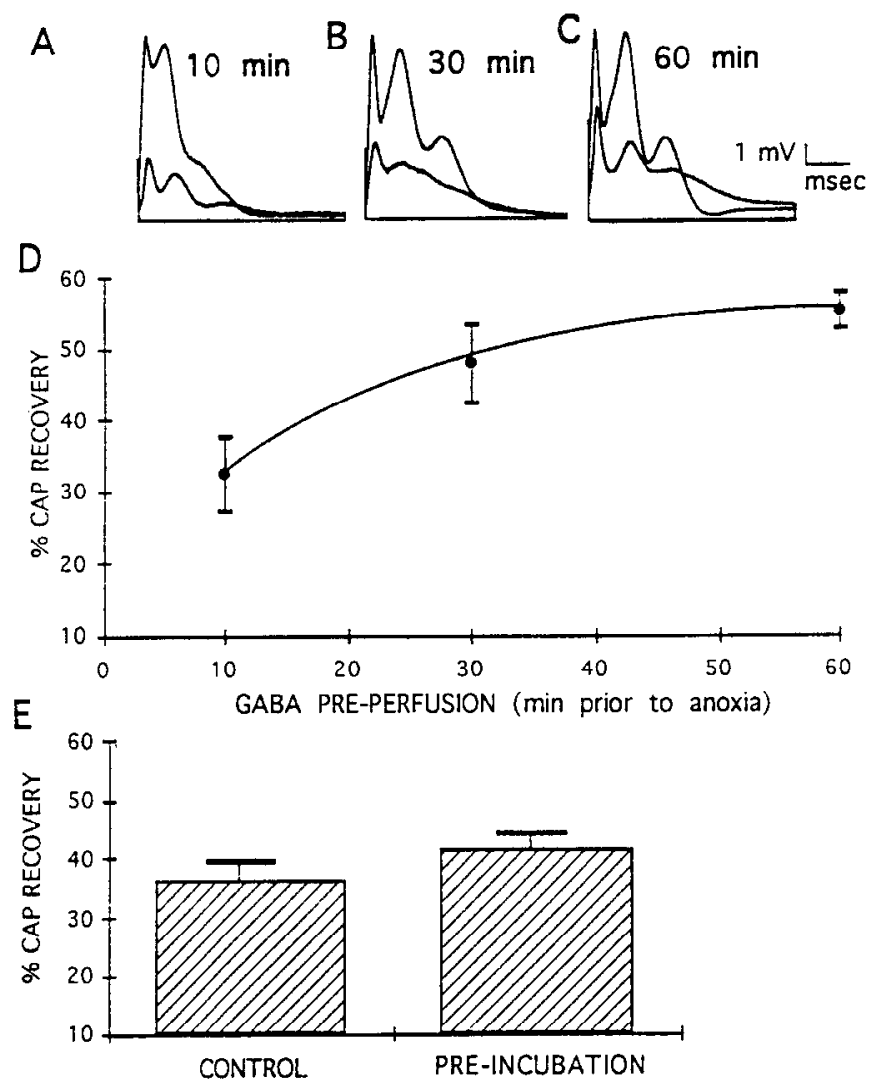

Figure 5. Time course of the development of GABA-mediated protection. One micromolar GABA perfusion was initiated at various times prior to the onset of anoxia. $A, \mathrm{GABA}$ applied $10 \mathrm{~min}$ prior to anoxia produced no protective effect. $B$, Thirty minutes of GABA perfusion prior to anoxia had a significant protective effect. $C$, Typical protection provided by 60 min of GABA perfusion prior to anoxia. $D$, Summary of the data showing mean \% CAP recovery from anoxia as a function of the period of preanoxic GABA perfusion. The curve was fitted by eye. $E$, Pretreatment with $1 \mu \mathrm{M}$ GABA for $60 \mathrm{~min}$ followed by $30 \mathrm{~min}$ of washout with aCSF prior to anoxia showed a similar level of recovery after anoxia $(41.6 \pm 2.8 \%, n=8)$ as untreated control nerves $(36.5 \pm$ $36.5 \%, n=12$ ).

addition, potassium diffuses very rapidly into our preparation (Fig. 1).

There are a variety of possible mechanisms by which GABA might protect the optic nerve from anoxic injury (see Discussion). To help distinguish whether GABA was acting via a reversible or an irreversible mechanism, we determined whether GABA pretreatment alone was sufficient to provide protection from anoxia. We perfused the rat optic nerve with $1 \mu \mathrm{M}$ GABA for $60 \mathrm{~min}$ and then washed GABA from the optic nerve with aCSF for $30 \mathrm{~min}$ prior to a $60 \mathrm{~min}$ anoxic period. No significant protection from anoxic injury was afforded by this period of pretreatment (Fig. $5 E$ ).

\section{Endogenous GABA release limits anoxic injury}

As experiments described above indicated that activation of GABA-B receptors protected optic nerve axons from anoxic injury, we examined whether these receptors were activated by GABA in situ during anoxia. Endogenous GABA release can be enhanced by nipecotic acid (Sakatani et al., 1992), which inhibits GABA uptake and stimulates GABA release (Brown and Marsh, 1978). If releasable GABA stores are present in the adult optic nerve, nipecotic acid would be expected to cause a rise in ex-

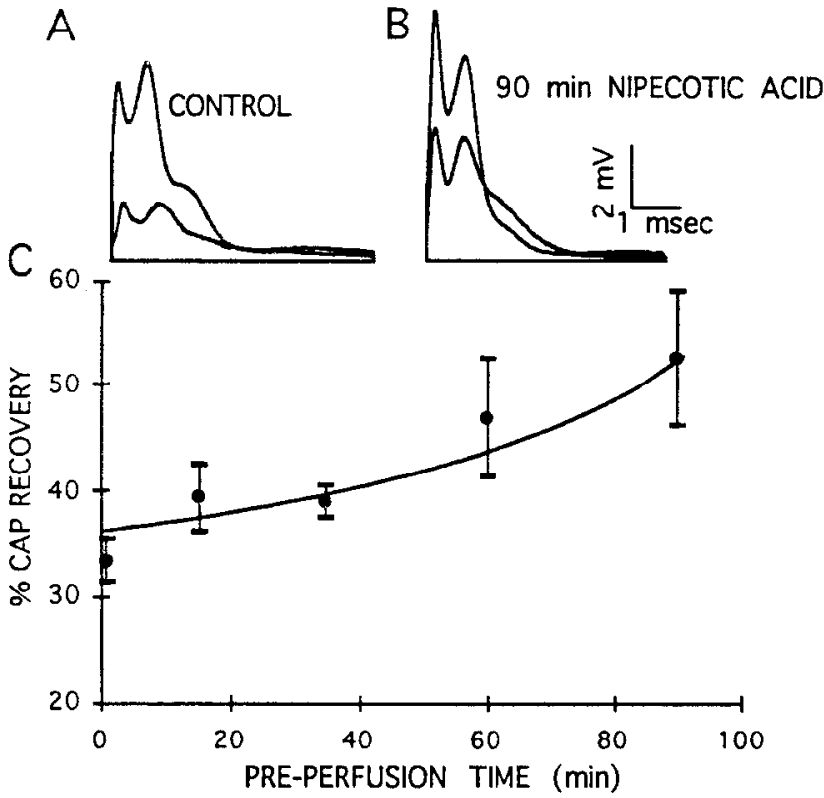

Figure 6. GABA released from endogenous stores protected against anoxia. $A$, Typical control recovery from the standard anoxic insult. $B$, Ninety minutes of perfusion prior to anoxia with the GABA reuptake blocker nipecotic acid provided protection from anoxia (mean recovery $=52.6 \pm 6.4 \%, n=8 ; p<0.02$ ). $C$, Relationship between \% CAP recovery and the period of nipecotic acid preperfusion. Preperfusion for 60 and $90 \mathrm{~min}$ periods provided significant protection $(p<0.05$ and $p<0.02$, respectively). Each point represents a mean of 6-14 experiments.

tracellular GABA concentration and provide protection against anoxic injury. One millimolar nipecotic acid (applied $90 \mathrm{~min}$ prior to the onset of anoxia and continually over the anoxic period) increased postanoxic CAP recovery compared to the control level (Fig. $6 A, B$ ). The mean \% CAP recovery for various periods of nipecotic acid perfusion are shown in Figure $6 C$, confirming the protective effect of nipecotic acid when applied for $90 \min (p<0.02)$.

An additional set of experiments was performed to examine whether endogenous GABA was present in high enough concentration in the rat optic nerve to moderate nerve fiber injury during anoxia when GABA uptake has not been interrupted. Optic nerves were perfused with the GABA-B receptor antagonists phaclofen or 5-aminovaleric acid (AVA) (Schwarz et al., 1988) to block any GABA-B receptor activation resulting from endogenous GABA release. Figure 3 shows that $500 \mu \mathrm{M}$ phaclofen blocked the protective action of $1 \mu \mathrm{M} \mathrm{GABA}$, and Figure 7 shows that GABA-B receptor blockade by phaclofen in the absence of exogenous GABA reduced the recovery found after anoxia, from a mean of $39.5 \pm 3.8 \%$ down to $23.6 \pm 3.8 \%$ ( $p$ $<0.005$; Fig. $7 A-C$ ). Presumably the same low level of recovery was not also found in Figure 3 due to the presence of $1 \mu \mathrm{M}$ GABA in the bath, which will partially displace phaclofen, a competitive antagonist of low potency. AVA also reduced recovery to below control value (mean CAP recovery $=26.5 \pm$ $3.5 \%, p<0.03$; Fig. $7 C$ ).

To test whether the GABA-B receptor antagonists might be neurotoxic to rat optic nerve axons, we employed a protocol similar to the above experiments but maintained the nerves in a normoxic environment. Although changes in CAP shape could follow prolonged GABA-B receptor blockade, neither $500 \mu \mathrm{M}$ 

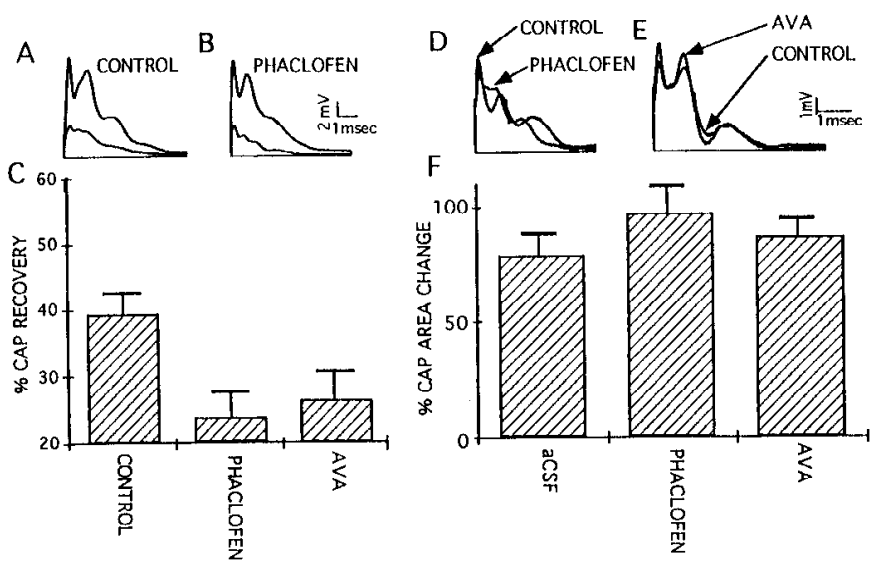

Figure 7. Endogenous GABA acted at GABA-B receptors to protect against anoxia. $A$. Typical control recovery from anoxia. $B$, Block of endogenous GABA-B receptor activation with $500 \mu \mathrm{M}$ phaclofen reduced recovery following anoxia from that found under control conditions: $C$, Summary of the data showing control CAP recovery of 39.5 $\pm 3.1 \%(n=13)$ compared to $23.6 \pm 3.8 \%(n=11)$ recovery in 500 $\mu \mathrm{M}$ phaclofen $(P<0.005)$ and recovery of $26.5 \pm 3.5 \%(n=8)$ in 1 mM AVA $(p<0.03)$, another GABA-B receptor antagonist. $D$ and $E$, Superimposed CAPs recorded prior to and subsequent to $120 \mathrm{~min}$ periods of perfusion with either $500 \mu \mathrm{m}$ phaclofen $(D)$ or $1 \mathrm{~mm}$ AVA $(E)$, in a normoxic environment. While changes in CAP shape were seen, there was no significant change in CAP area following GABA-B receptor block, compared to control. Mean CAP area after $120 \mathrm{~min}$ of phaclofen perfusion was $97.2 \pm 11.9 \%$ of the initial area $(n=6)$ and after 120 min AVA CAP area was $86.5 \pm 8.4 \%(n=6)$; these changes in CAP area were not significantly different from that found after $120 \mathrm{~min}$ of perfusion with aCSF $(78.4 \pm 9.5 \%$ of the initial CAP area, $n=6)$.

phaclofen nor $1 \mathrm{mM}$ AVA caused significant changes in CAP area (Fig. $7 D-F)$. Mean CAP area was $97.2 \pm 11.9 \%(n=6)$ of the initial area after $120 \mathrm{~min}$ of phaclofen perfusion, and 86.5 $\pm 8.4 \%(n=6)$ of initial area after $120 \mathrm{~min}$ of $1 \mathrm{~mm}$ AVA perfusion (compared to $78.4 \pm 9.5 \%$ after $120 \mathrm{~min}$ of perfusion with aCSF). These control experiments indicated that endogenous GABA indeed acted to protect the optic nerve during anoxia.

\section{$G A B A-B$ receptors recruit a $G$-protein/PKC-mediated intracellular pathway}

The involvement of a G-protein in GABA-mediated protection from anoxia was assessed using pertussis toxin (PTX), which is known to irreversibly block the biological activity of some G-proteins (Ui, 1984). Rat optic nerves were perfused for 120 min with $200 \mathrm{ng}$ PTX prior to a $60 \mathrm{~min}$ period of $1 \mu \mathrm{M}$ GABA perfusion and subsequent anoxia. Following PTX pretreatment, there was significantly less recovery than in control experiments performed using the same protocol but in the absence of PTX. Mean CAP recovery following PTX pretreatment was $38.7 \pm$ $3.9 \%$ compared to $53.6 \pm 4.0 \%$ when PTX was omitted $(P<$ 0.02 ; Fig. $8 A, D$ ). CAPs recorded following $120 \mathrm{~min}$ of PTX trcatment and $60 \mathrm{~min}$ perfusion with aCSF were of normal shape and area compared to CAPs perfused in aCSF alone. This suggests that PTX was not toxic to the optic nerves and was not acting in a nonspecific fashion to reduce CAP recovery during anoxia.

Cyclic AMP is an important second messenger which regulates a number of neuronal conductances. We examined whether cAMP was involved in GABA-mediated protection from anoxia by employing the membrane-permeable cAMP analogue di-
A
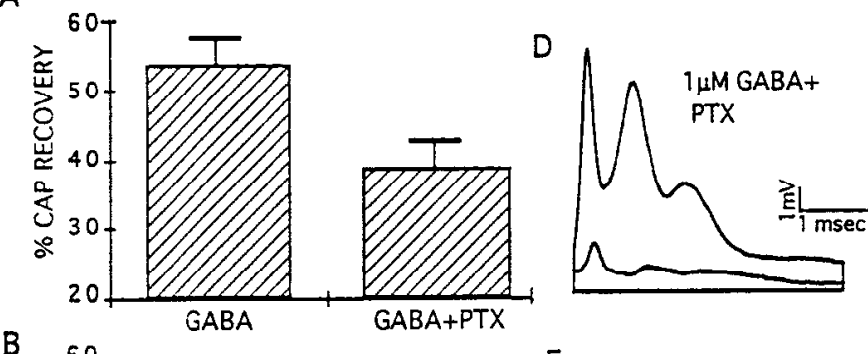

B
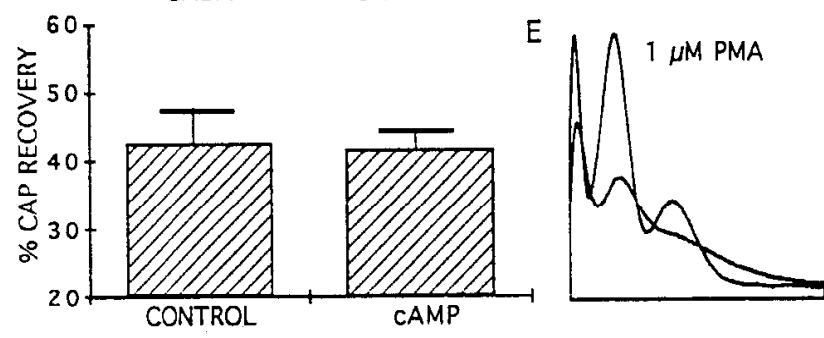

C

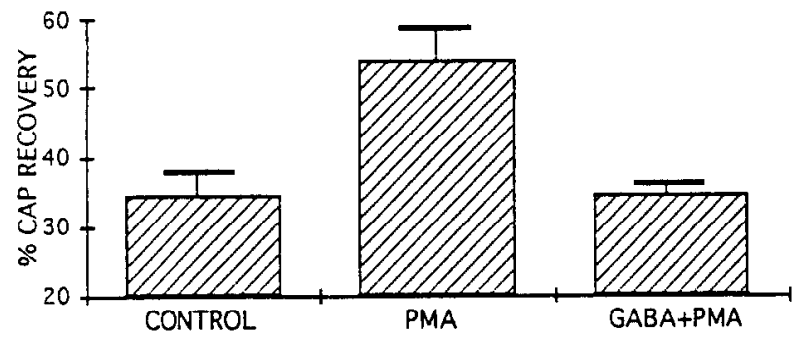

Figure 8. Pertussis toxin (PTX) blocked and PKC activation mimicked the protective action of GABA. $A$ and $D$, Mean CAP recovery in $1 \mu \mathrm{M}$ GABA, applied $60 \mathrm{~min}$ prior to anoxia and following an initial $120 \mathrm{~min}$ period of pcrfusion with aCSF, was $53.6 \pm 4.0 \%(n=7)$. When aCSF was substituted with aCSF containing $200 \mathrm{ng} / \mathrm{ml}$ PTX, the protection produced by $1 \mu \mathrm{M}$ GABA was reduced (mean CAP recovery $=38.7 \pm$ $3.9 \%, n=8)$. $B$, CAP recovery in dibutryl cAMP, a membrane-permeable form of cAMP, was not different from control CAP recovery $(42.6 \pm 4.9 \%, n=8$ compared to $41.6 \pm 3.3 \%, n=8)$. $C$ and $E$, Perfusion with $1 \mu \mathrm{M}$ PMA (an activator of PKC) increased recovery from anoxia from $34.3 \pm 3.6 \%(n=13)$ to $53.9 \pm 4.7 \%(n=12, p<$ $0.003)$. One micromolar of PMA applied simultaneously with $1 \mu \mathrm{M}$ GABA occluded the protection normally provided by GABA (mean CAP recovery $=34.5 \pm 1.4 \%, n=8$ ).

butryl cAMP. One millimolar dibutryl cAMP was applied to the nerves $60 \mathrm{~min}$ prior to the onset of anoxia and mean CAP recovery was not significantly altered from control recovery $(42.6 \pm 4.9 \%$ compared to $41.6 \pm 3.3 \%$, respectively; $p>0.8$ Fig. $8 B$ ). It appeared, therefore, that an intracellular pathway involving elevation of cAMP was not an important element in GABA-mediated protection from anoxia.

Neuronal voltage-gated ion channels and ion exchangers in various cell types can be modulated by PKC (Hidaka et al., 1984; Vasilets et al., 1990; Mené et al., 1991; West et al., 1991; Dascal and Lotan, 1991; Gomez et al., 1993), and PKC is known to be activated by GABA-B receptors (see Borman, 1989). To test for the involvement of a PKC-linked intracellular pathway, we employed 12-myristate 13-acetate (PMA), a selective PKC activator. Perfusion with $1 \mu \mathrm{M}$ PMA for $60 \mathrm{~min}$ prior to anoxia resulted in a significant increase in the degree of postanoxic recovery $(53.9 \pm 4.7 \%$ compared to $34.1 \pm 4.7 \%, p<0.01$; Fig. 8C,E). If GABA does recruit a PKC-mediated intracellular pathway during anoxia, addition of PMA with $1 \mu \mathrm{M}$ GABA should affect the degree of protection provided by the GABA. We found that coapplication of PMA with $1 \mu \mathrm{M}$ GABA occluded 


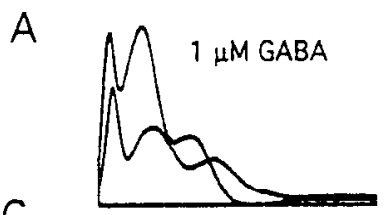

B
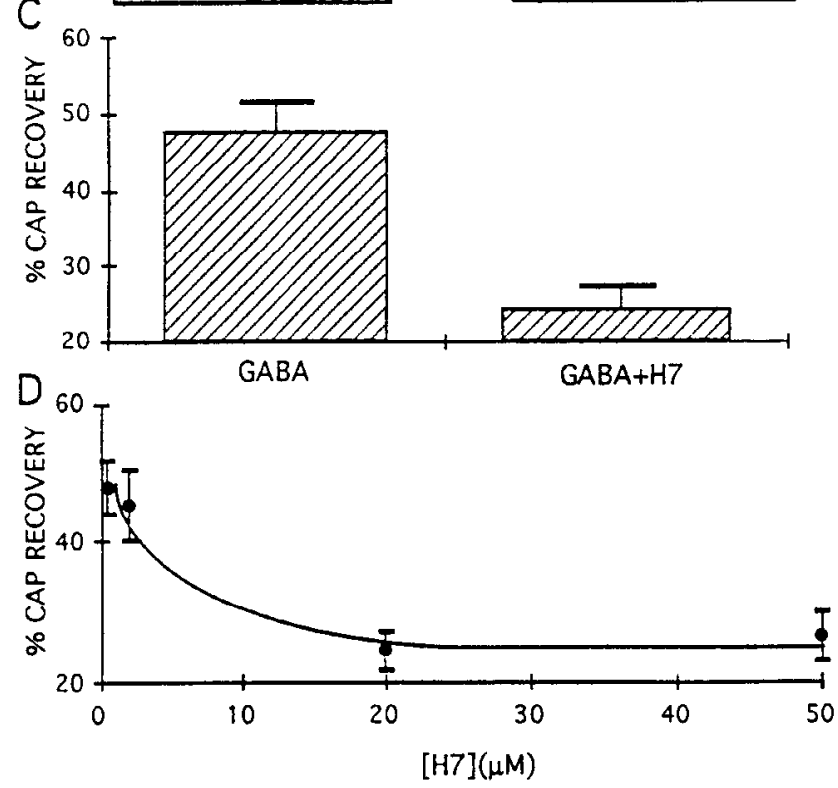

Figure 9. Block of $\mathrm{PKC}$ with $\mathrm{H} 7$ removed the protective effect of GABA. A, Pre- and postanoxic CAPs recorded in the presence of $1 \mu \mathrm{M}$ GABA. $B$, Recordings from a similar experiment but in the presence of $20 \mu \mathrm{M} \mathrm{H} 7$, a PKC inhibitor (applied 10 min prior to GABA). C, Data summary showing that inhibition of PKC $(20 \mu \mathrm{M} \mathrm{H7})$ removed the protective effect of GABA. Recovery in the absence of $\mathrm{H} 7$ was $47.7 \pm$ $3.7 \%(n=7)$ compared to $24.4 \pm 2.7 \%(n=11)$ in $\mathrm{H} 7(p<0.0001)$. Note that recovery in the presence of $\mathrm{H} 7$ was lower than that normally found under control conditions. $D$, Dose-response relationship for $\mathrm{H} 7$ inhibition of GABA-mediated protection ( $n=7$ to 11 ) demonstrating that $\mathrm{H} 7$ was effective over a concentration range consistent with selective inhibition of PKC.

the protection normally produced by GABA (mean CAP recovery in $1 \mu \mathrm{M}$ GABA $+1 \mu \mathrm{M}$ PMA $=34.5+1.4 \%, n=8$; Fig. $8 C$ ). These results indicate that any additional recruitment of the PKC-mediated pathway beyond that produced by $1 \mu \mathrm{M}$ GABA alone resulted in a reduction in the degree of postanoxic CAP recovery, as predicted by Figure 4.

To further test the role of PKC, we employed the widely used PKC antagonist 1-(5-isoquinolinesulfonyl)-2-methylpiperazine dihydrochloride (H7). Specimen records of representative preand postanoxic CAPs recorded in the presence of $1 \mu \mathrm{M}$ GABA $\pm 20 \mu_{\mathrm{M} \mathrm{H}} \mathrm{H}$ (added $10 \mathrm{~min}$ prior to the addition of GABA) illustrate that $\mathrm{H} 7$ abolished the protective effect of $1 \mu \mathrm{M}$ GABA (Fig. 9A,B). CAP recovery with $1 \mu \mathrm{M}$ GABA alone was $47.8 \pm$ $3.7 \%$ and with both $\mathrm{H} 7$ and GABA present was reduced to 24.4 $\pm 2.7 \%$ ( $p<0.0001$; Fig. $9 C)$.

Inhibition of PKC with II7 occurs over a 2-50 $\mu \mathrm{M}$ concentration range (Hidaka et al., 1984; Kawamoto and Hidaka, 1984; Nakadate et al., 1990; Chakrabarty et al., 1992), with a reported $K_{i}$ of $6 \mu \mathrm{M}$ (Hidaka et al., 1984). The dose-response relationship for $\mathrm{H} 7$ inhibition of GABA protection from anoxic injury (Fig. $9 D$ ) showed that $\mathrm{H} 7$ inhibited GABA protection over a similar concentration range. However, $\mathrm{H} 7$ has inhibitory effects upon cAMP-dependent protein kinases as well upon PKC. We therefore employed the more specific and potent PKC inhibitor stau-
A
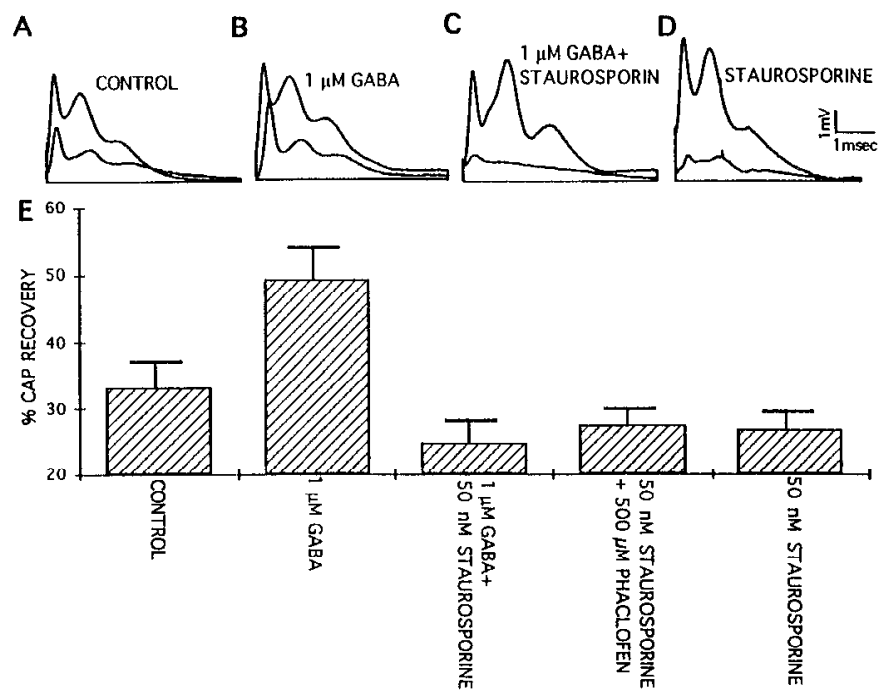

Figure 10. PKC inhibition with staurosporine removed the protective effect of GABA. $A$, CAP recovery from anoxia in the absence of GABA. $B$, Increased CAP recovery found in the presence of GABA. $C$, Perfusion of $50 \mathrm{nM}$ staurosporine, initiated $10 \mathrm{~min}$ prior to perfusion with $1 \mu \mathrm{M}$ GABA, reduced CAP recovery to below control levels. $D$, Staurosporine alone reduced the level of postanoxic CAP recovery, compared to control recovery. $E$, Data summary showing the abolition of GABA protection by staurosporine: mean CAP recovery under control conditions was $33.2 \pm 3.9 \%(n=11), 49.2 \pm 4.9 \%(n=8)$ in the presence of GABA, and $24.6 \pm 3.4 \%(n=7)$ in GABA + staurosporine. CAP recovery in staurosporine + GABA was significantly different from in GABA alone $(p<0.001)$. The effect of staurosporine could not be accounted for by a nonspecific toxic effect. Coadministration of staurosporine and $500 \mu \mathrm{M}$ phaclofen produced a level of CAP recovery similar to that found in the presence of staurosporine alone (mean CAP recovery $=27.4 \pm 2.5 \%, n=7 ; P<0.05$ ). Staurosporine, administered alone, reduced the level of CAP recovery from that found under control conditions (mean CAP recovery $=26.8 \pm 2.6 \%$, compared to control recovery of $39.8 \pm 2.9 \%, p<0.05$ ). This suggests that an endogenous, PKC-dependent process helped to protect rat optic nerves against anoxia.

rosporine (Tamaoki et al., 1986) to confirm the role of PKC during GABA-mediated protection. Control, $1 \mu \mathrm{M}$ GABA, and $1 \mu \mathrm{M}$ GABA $+50 \mathrm{nM}$ staurosporine experiments are shown in Figure $10 A-E$, showing mean recovery of $33.2 \pm 3.9 \%, 49.2 \pm$ $4.9 \%$, and $24.6 \pm 3.4 \%$, respectively. Recovery in the presence of GABA + staurosporine was significantly lower than in the presence of GABA alone ( $p=0.001)$. Indeed, recovery in the presence of GABA during PKC inhibition with either $\mathrm{H} 7$ or staurosporine was lower than under control conditions and corresponded to that observed during GABA-B receptor blockade.

The low recovery found with staurosporine cannot be accounted for by a toxic effect of the drug during anoxia. Thus, coapplication of $50 \mu \mathrm{M}$ staurosporine with $500 \mu \mathrm{M}$ phaclofen, where GABA-B receptor-mediated protection will be inhibited by phaclofen and any toxic effect of staurosporine would be expected to result in a lower level of CAP recovery compared to that found in phaclofen alone, produced CAP recovery similar to the application of either staurosporine alone or phaclofen alone $(27.4 \pm 2.5 \%, n=7$; Fig. $10 E ; 23.6 \pm 3.5 \%$, Fig. 7 , respectively). To assess whether endogenous GABA protected white matter during anoxia via recruitment of the PKC-mediated pathway that underlies the protective effect of exogenous GABA, we perfused optic nerves with staurosporine alone. Mean CAP recovery in $50 \mathrm{~nm}$ staurosporine was $26.8 \pm 2.6 \%$, which 
was significantly lower than the control recovery of $39.8 \pm 2.9 \%$ $(p<0.05$; Fig. $10 D, E)$.

$P K C$ activation does not influence normoxic nerve conduction in rat optic nerve axons

PKC activation is known to inhibit voltage-gated sodium channels (Hidaka et al., 1984; Dascal and Lotan, 1991; West et al., 1991; Gomez et al., 1993). Since voltage-gated sodium channels are responsible for the generation and conduction of action potentials in axons, PKC activation may influence nerve conduction (Rang and Ritchie, 1988; Meiri and Gross, 1989). However, the effect of PKC activation upon the optic nerve CAP area and peak latency was found to be negligible (Fig. 11A-E). Similar results were found in six other optic nerves. Data from 12 optic nerves from a separate series of experiments were pooled in Figure $11 F$, which shows the mean CAP area following initiation of 60 min perfusion with $1 \mu \mathrm{M}$ PMA. No change in CAP area was found, indicating that in the rat optic nerve PKC activation did not influence nerve conduction.

\section{Discussion}

Our results support a novel functional role for the ubiquitous inhibitory neurotransmitter GABA in CNS white matter. GABA released from endogenous stores acted on GABA-B receptors to significantly improve CAP recovery in the optic nerve following anoxia. The evidence also implies that GABA's protective effect was mediated via a G-protein/PKC intracellular pathway. These findings were unexpected for many reasons. Prior studies indicate that GABA can influence peripheral axons (Brown and Marsh, 1978; Arenson and Nistri, 1983; Morris et al., 1983a,b; Liske and Morris, 1989) and neonatal CNS axons (Sakatani et al., 1992; Lee et al., 1993), but actions upon mature myelinated CNS axons are either small or nonexistent (Simmonds, 1983; Sakatani et al., 1991a, 1992). Observed GABA effects on axons have thus far always been mediated by GABA-A receptors; that is, they have depended on chloride ions, have been blocked by bicuculline, and have been activated by selectivc GABA-A agonists such as THIP and muscimol. The effect of GABA on white matter anoxic injury reported here was robust and mediated by GABA-B receptors. Given the low concentration of GABA that was necessary for protection against anoxic injury, there is reason to think that GABA might act in the same protective manner in vivo. These observations, therefore, suggest the possibility that enhancement of brain GABA levels may improve neurologic outcome following anoxic insults such as strokes, nearly a quarter of which are located solely in the white matter of the brain (Fisher, 1982; Bamford et al., 1987).

GABA has previously been implicated in protection from anoxia in a number of anoxia-resistant species, such as freshwater turtles and crucian carp (Hitzig et al., 1985; Lutz et al., 1985; Nilsson et al., 1990; Nilsson and Lutz, 1991; Lutz, 1992). In these species, both total brain GABA concentration (Hitzig et al., 1985; Lutz et al., 1985) and extracellular GABA concentration (Nisson and Lutz, 1991) rise significantly during anoxia. It has been suggested that in these species GABA release inhibits neuronal activity to limit energy use (Lutz, 1992), but the current data suggest a different and more complex action of GABA in the anoxic mammalian brain.

We have found that low concentrations of GABA protect rat optic nerve axons against anoxic injury via a sequence of steps, as shown in Figure 12. Development of anoxic damage in white matter is dependent upon the presence of extracellular sodium

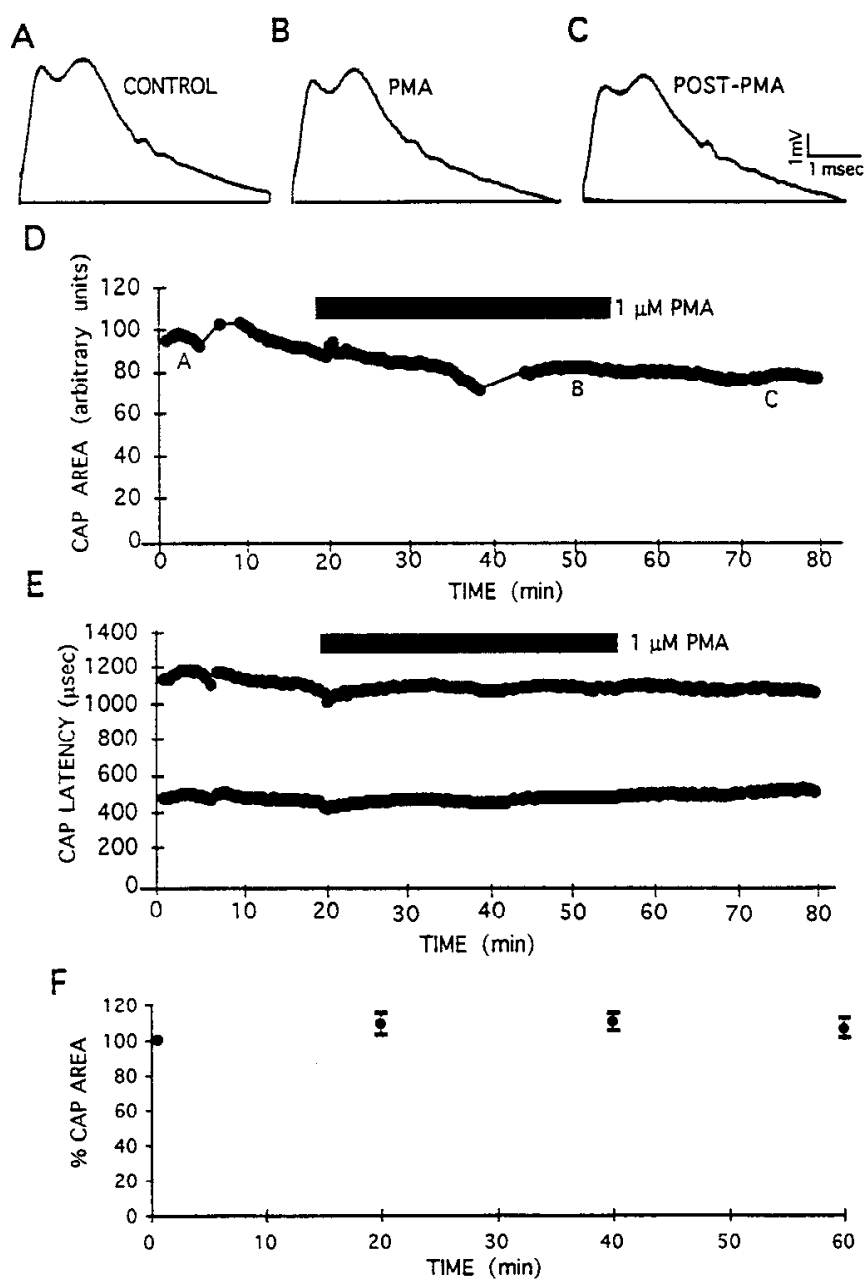

Figure 11. PKC activation does not significantly effect the normoxic CAP in the rat optic nerve. $A-C$, CAPs recorded from the same optic nerve prior to, during, and following a $35 \mathrm{~min}$ period of $1 \mu \mathrm{M}$ PMA treatment. $D$, A plot of CAP area showing the complete data set from which $A-C$ were drawn (as indicated by the appropriate letters). $E, A$ plot similar to $D$ showing the conduction latency (time between stimulation and the first and second peaks of the CAP) for the same nerve as in $D . F$, Mean change in CAP area in 12 nerves following the initiation of $1 \mu \mathrm{M}$ PMA perfusion (different experiments from $A-E$ ). There is no significant effect of PMA upon any of the conduction parameters.

and calcium ions (Stys et al., 1990, 1992). Sodium ions enter the intracellular compartment during anoxia through "persistent" or noninactivating sodium channels (Stys et al., 1992, 1993) following the membrane depolarization which results from the efflux and accumulation of potassium ions (Ransom et al., 1992; Ransom and Philben, 1993). This degrades the normal transmembrane sodium ion gradient, promoting calcium ion entry via reverse operation of the $\mathrm{Na}^{+} / \mathrm{Ca}^{2+}$ exchanger leading to calcium-mediated injury (Waxman et al., 1992, 1993) with concomitant loss of CAP recovery (Stys et al., 1990, 1992).

The pharmacology of GABA protection indicated that GABA acted at the GABA-B receptor. Thus, GABA's action was insensitive to bicuculline and was not mimicked by selective GABA-A agonists, while being sensitive to GABA-B antagonists and mimicked by the selective GABA-B agonist baclofen. Blocking GABA uptake with nipecotic acid, which presumably incrcascs the concentration of endogenous GABA in the cxtracellular space (Sakatani et al., 1992), acted to increase post- 


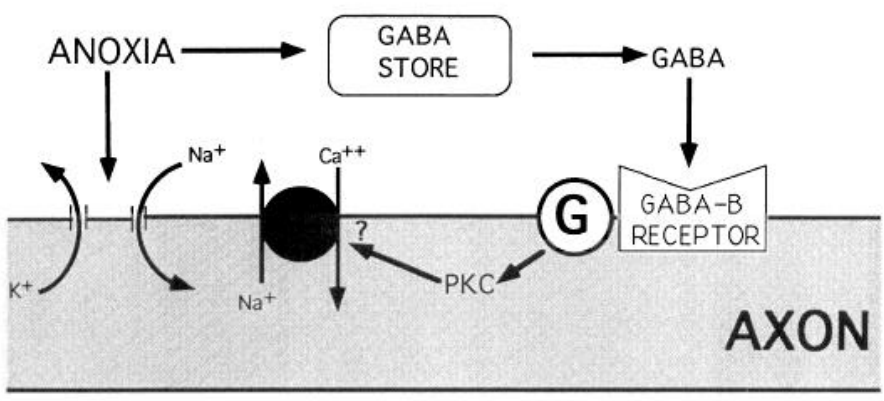

Figure 12. A model for the protective effect of GABA during anoxia in rat optic nerve. During anoxia, $\mathrm{K}^{+}$efflux and $\mathrm{Na}^{+}$influx lead to reverse operation of the $\mathrm{Na}^{+} / \mathrm{Ca}^{2+}$ exchanger and $\mathrm{Ca}^{2+}$ influx. Anoxia also induces release of GABA from a site endogenous to the nerve ("GABA store"). The resulting increase in extracellular GABA concentration triggers the activation of GABA-B receptors and initiates an intracellular pathway involving a G-protein/PKC cascade. The optic nerve axons are made more resistant to anoxia as a result. The target of PKC phosphorylation is unknown but could be the $\mathrm{Na}^{+} / \mathrm{Ca}^{2+}$ exchanger, phosphorylation and subsequent downregulation of which would limit $\mathrm{Ca}^{2+}$ influx (see text).

anoxic recovery. In addition, blocking the GABA-B receptor in the absence of exogenous GABA reduced the degree of recovery seen following anoxia. These results lead us to conclude that (1) GABA-B receptor activation protected optic nerve axons from anoxic injury, (2) mature optic nerves contained stores of GABA capable of release, and (3) optic nerve GABA stores are capable of raising extracellular GABA concentration to a level which protected optic nerve axons from anoxic injury. This intrinsic, GABA-mediated cascade may constitute an autoprotective mechanism directed against the development of irreversible dysfunction.

The mechanism underlying the protective effect of GABA is only partially understood. GABA-B receptor activation was apparently linked to the recruitment of an intracellular second messenger pathway involving a PTX-sensitive G-protein. Protection was removed by $\mathrm{H} 7$ over a concentration range where this compound inhibits PKC, and by the more specific PKC inhibitor staurosporine. In addition, activation of $\mathrm{PKC}$ with PMA mimicked the effects of GABA, while coadministration of PMA with GABA occluded the protection normally provided by GABA. Thus we can conclude that GABA protected white matter from anoxia by activating a GABA-B receptor/G-protein/PKC cascade which presumably phosphorylated a target protein to increase resistance to anoxia. Phosphorylation of the target protein was apparently reversible as removal of GABA $30 \mathrm{~min}$ prior to anoxia failed to produce any increase in resistance to anoxia.

\section{$P K C$ activation does not influence CAP conduction in the rat optic nerve}

PKC activation results in rapid modification of voltage-gated ion channels in neurons (Hidaka et al., 1984; Dascal and Lotan, 1991; Gomez et al., 1993). Such changes can have significant consequences for action potential conduction, as demonstrated in peripheral nerves (Rang and Ritchie, 1988; Meiri and Gross, 1989). We found no significant change in the rat optic nerve CAP following activation of PKC. It is possible that axonal sodium channels were fully phosphorylated in the isolated rat optic nerve.

\section{$G A B A$ in $C N S$ white matter}

GABA is widely distributed throughout the CNS, being present not only in gray matter but also in white matter (Balcom et al., 1975; Van De Hayden et al., 1979; Anden et al., 1987; Lake, 1992; Ochi et al., 1993; Shimada et al., 1993). Both GABA-A and GABA-B receptors are also found in white matter (Bowery et al., 1987; Chu et al., 1990), although GABA and its receptors occur in lower concentrations in white matter than in gray matter. However, the smaller amount of excitable membrane in white matter may be an important factor in determining the functional significance of differences in receptor density between brain regions. Thus, only approximately $0.5 \%$ of the length of optic nerve fibers is excitable (Butt and Ransom, 1989), compared to a much larger fraction of the neuronal somatic, dendritic, and preterminal axon membranes which are present in gray matter. Even if the functional density of GABA receptors was similar in excitable membranes of gray and white matter, a smaller total number of white matter GABA receptors would be expected.

GABA stores in mature CNS white matter are probably localized in glial cells. White matter astrocytes possess the capability to take up extracellular GABA (Siemers et al., 1982) and to accumulate GABA when degradation enzymes are inhibited (Bull and Blomqvist, 1991), and GABA-positive glia have been demonstrated in mature optic nerve (Lake, 1992; but see also Ochi et al., 1993). In addition, GABA-positive axons have been identified in a number of sites in the CNS, including the optic nerve (Mosinger et al., 1986; Koontz et al., 1989; Radian et al., 1990; Todd and Sullivan, 1990; Davanger et al., 1991), suggesting that axons may represent another possible source of GABA in white matter.

The protective effect of GABA increased over a $10 \mathrm{nM}-1 \mu \mathrm{M}$ concentration range. Concentrations higher than $1 \mu \mathrm{M}$ had progressively less effect, possibly due to receptor desensitization. Block of GABA-B receptors reduced recovery from anoxia, indicating that the endogenous GABA concentration was high enough to protect optic nerves during anoxia. Mean CAP recovery under control conditions was approximately $36 \%$, which lies between the mean CAP recovery found during GABA-B receptor block (presumably the recovery seen in zero extracellular GABA) and perfusion with $10 \mathrm{~nm}$ GABA. These data are therefore consistent with a GABA concentration close to the value of $20 \mathrm{~nm}$ reported in normoxic white matter by Shimada et al. (1993).

Conditions during anoxia are ideal for release of GABA following reversal of uptake transport (Blaustein and King, 1976; Carvalho et al., 1991; Ransom et al., 1992; Stys et al., 1992). Indeed, Shimada et al. (1993) have reported that GABA concentration in white matter increases during ischemia, reaching levels as high as $0.1 \mu \mathrm{M} 120 \mathrm{~min}$ after the blood supply to the brain had been partially interrupted. Furthermore, Anden et al. (1989) reported that GABA concentration increased by $200 \%$ in isolated white matter post mortem, an effect thought to be due to anoxia (Baxter, 1976).

\section{The mechanism of action of GABA recruitment of an intracellular pathway}

GABA-B receptor activation could interrupt the cascade of events which leads to irreversible anoxic injury at a number of points. For example, GABA-B receptor activation influences ionic conductances in a variety of neuronal cell types (for review see 
Borman, 1989), and ion flux through channels is essential to the development of anoxic injury in white matter (Stys et al., 1992). Alternatively, recruitment of the GABA-B receptor/G-protein/ PKC second messenger system could result in downregulation of membrane transporters, such as the $\mathrm{Na}^{+} / \mathrm{Ca}^{2+}$ exchanger (Mené et al., 1991), that participate in the development of anoxic injury (Stys et al., 1992). An effect of GABA upon ATP metabolism during the early stages of anoxia could also underlie the protection provided by GABA. It is unclear, however, how the intracellular pathway we have described could produce a direct modulation of ATP breakdown.

Downregulation of the $\mathrm{Na}^{+} / \mathrm{Ca}^{2+}$ exchanger or inactivation of persistent sodium channels would produce a protective effect consistent with our data. GABA-mediated protection was found to be relatively slow to develop and was fully reversible. Downregulation and internalization of membrane transporters have similar characteristics (Schmalzing et al., 1990; Vasilets et al., 1990), while inactivation of axonal ion channels by phosphorylation is both rapid and irreversible (Rang and Ritchie, 1988). The results are therefore more consistent with the idea that downregulation of the $\mathrm{Na}^{+} / \mathrm{Ca}^{2+}$ transporter underlies GABAmediated protection in white matter (see Fig. 12), although effects upon ion channels cannot be excluded.

It is interesting to consider these possible actions of GABA in relation to results that have been reported in chronic experiments using the GABA degradation inhibitor vigabatrin. Vigabatrin increases the levels of GABA in the brain and is used clinically in the treatment of epilepsy. In animal studies it has been shown that while vigabatrin has no pathological actions upon gray matter, it causes microvacuolization in white matter (Butler et al., 1987; Butler, 1989; Sabers and Gram, 1992). These ultrastructural changes are similar to those seen in white matter following anoxia (Waxman et al., 1992). Conceivably, vigabatrin's pathological effects on white matter might result from a sustained extracellular GABA increase which induces a downregulation of the $\mathrm{Na}^{+} / \mathrm{Ca}^{2+}$ exchanger. During anoxia, GABA elevation would be beneficial since temporary downregulation of the $\mathrm{Na}^{+} / \mathrm{Ca}^{2+}$ exchanger would block or reducc $\mathrm{Ca}^{2+}$ loading by reverse exchange. In contrast, under normoxic conditions sustained GABA elevation would compromise the ability of white matter to regulate intracellular $\mathrm{Ca}^{2+}$ in a normal manner.

\section{References}

Alger BE, Nicoll RA (1982) Pharmacological evidence for two kinds of GABA receptor on rat hippocampal pyramidal cells studied in vitro. J Physiol (Lond) 328:125-141.

Anden N-E, Lindgren S, Magnusson A (1987) Regional differences in the changes in rat brain GABA concentration post mortem and following inhibition of synthesis and metabolism. Pharmacol Toxicol 60:393-396.

Arenson MS, Nistri A (1983) The inhibitory amino acid GABA hyperpolarizes motor axons: an intracellular study. Experientia 39:225228 .

Atwell A, Barbour B, Szatkowski M (1993) Nonvesicular release of neurotransmitter. Neuron 11:401-407.

Balcom GJ, Lenox RH, Meyerhoff JL (1975) Regional $\gamma$ aminobutyric acid levels in rat brain determined after microwave fixation. J Neurochem 24:609-613.

Bamford J, Sandercock P, Jones L, Warlow C (1987) The natural history of lacunar infarction: the Oxfordshire community stroke project. Stroke 18:545-551.

Baxter $\mathrm{CF}$ (1976) Some recent advances in studies of GABA metabolism and compartmentation. In: GABA in nervous system function (Roberts E, ed), pp 61-87. New York: Raven.

Blaustein MP, King AC (1976) Influence of membrane potential on the sodium-dependant uptake of gamma-aminobutyric acid by pre- synaptic nerve terminals: experimental observations and theoretical considerations. J Membr Biol 30:153-173.

Borman N (1989) GABA-B receptors and their significance in mammalian pharmacology. Trends Pharmacol Sci 10:407-410.

Bowery NG (1993) GABA-B receptor pharmacology. Annu Rev Pharmacol Toxicol 33:109-147.

Bowery NG, Hudson AL, Price GW (1987) GABA-A and GABA-B receptor site distribution in the rat central nervous system. Neuroscience 20:365-385.

Brown DA, Marsh S (1978) Axonal GABA-receptors in mammalian peripheral nerve trunks. Brain Res 156:187-191.

Bull MS, Blomqvist A (1991) Immunocytochemical identification of GABA in astrocytes located in white matter after inhibition of GABAtransaminase with gamma-acetylenic GABA. J Neurocytol 20:290298.

Butler WH (1989) The neuropathology of vigabatrin. Epilepsia 30 [Suppl 3]:S15-S17.

Butler WH, Ford GP, Newberne JW (1987) A study of the effects of vigabatrin in the central nervous system and retina of Sprague-Dawley and Lister hooded rats. Pharmacol Toxicol 15:143-148.

Butt AM, Ransom BR (1989) Visualization of oligodendrocytes and astrocytes in the intact rat optic nerve by intracellular injection of lucifer yellow and horseradish peroxidase. Glia 2:470-475.

Carvalho CM, Bandeira-Duarte C, Fcrrcira IL, Cavalho AP (1991) Regulation of carrier-mediated and exocytotic release of [ $\left.{ }^{3} \mathrm{H}\right] \mathrm{GABA}$ in rat brain synaptosomes. Neurochem Res 16:763-772.

Chakrabarty S, Chen JW-J, Chen XY, Trujillo JM, Lin PF (1992) Modulation of differentiation-related responses in human colon carcinoma cells by protein kinase inhibitor H-7. Anticancer Res 12:97104.

Chu DC, Albin RL, Young AB, Penney JB (1990) Distribution and kinetics of GABA-B binding sites in rat central nervous system: a quantitative autoradiographic study. Neuroscience 34:341-357.

Cummins KL, Perkel DH, Dorfman LJ (1979) Nerve fibre conduction velocity distributions. I. Estimation based on the single fibre and compound action potentials. Electroencephalogr Clin Neurophysiol 46:634-646.

Dascal N, Lotan I (1991) Activation of protein kinasc C altcrs voltage dependence of an $\mathrm{Na}+$ channel. Neuron 6:165-175.

Davanger S, Ottersen OP, Storm-Mathiesen J (1991) Glutamate, GABA and glycine in the human retina: an immunocytochemical investigation. J Comp Neurol 311:483-494.

Davis P, Ransom BR (1987) Anoxia and CNS white matter: in vitro studies using the rat optic nerve. Soc Neurosci Abstr 13:1634.

De Luca C, Massotti M (1990) Phaclofen antagonizes the antinociceptive but not the sedative effects of (-)-baclofen. Prog Neuropsychopharmacol Biol Psychiatry 14:597-607.

Fisher CM (1982) Lacunes: small deep cerebral infacts. Neurology 15: 774-784.

Gomez J, Casado M, Gimenez C, Aragon C (1993) Inhibition of highaffinity gamma-aminobutyric acid uptake in primary astrocyte cultures by phorbol esters and phospholipase C. Acta Ncurol Bclg 275: 433-439.

Granda RH, Ten Eyck GR, Crossland WJ (1991) Chicken optic tract cells showing GABA-like immunoreactivity: morphological and immunocytochemical studies. J Comp Neurol 303:424-434.

Hidaka H, Inagaki M, Kawamoto S, Sasaki Y (1984) Isoquinolinesulfonamides, novel and potent inhibitors of cyclic nucleotide dependent protein kinase C. Biochemistry 23:5036-5041.

Hitzig BM, Kneussl MP, Shih V, Brandstetter RD, Kazemi H (1985) Brain amino acid concentrations during diving and acid-base stress in turtles. J Appl Physiol 58:1751-1754.

Kawamoto S, Hidaka H (1984) 1-(5isoquinolinesulfonyl)-2-methylpiperazine ( $\mathrm{H}-7)$ is a selective inhibitor of protein kinase $\mathrm{C}$ in rabbit platelets. Biochem Biophys Res Commun 125:258-264.

Koontz MA, Hendrickson AE, Ryan MK (1989) GABA-immunoreactive synaptic prexus in the nerve fibre layer of primate retina. Visual Neurosci 2:19-25.

Kriegler S, Chiu SY (1993) Calcium signaling of glial cells along mammalian axons. J Neurosci 13:4229-4245.

Lake N (1992) Taurine, GABA and GFAP immunoreactivity in the developing and adult rat optic nerve. Brain Res 596:124-132.

Lee M, Sakatani K, Young W (1993) A role of GABA-A receptors in hypoxia-induced conduction failure of neonatal rat spinal dorsal column axons. Brain Res 601:14-19. 
Lieberman EM, Abbott NJ, Hassan S (1989) Evidence that glutamate mediates axon-to-Schwann cell signaling in the squid. Glia 2:94-102.

Liske S, Morris ME (1989) Effects of GABA, THIP, and potassium on excitability of myelinated axons of isolated amphibian spinal roots. Can J Physiol Pharmacol 67:682-685.

Liu D, McAdoo DL (1993) An experimental model combining microdialysis with electrophysiology, histology, and neurochemistry for exploring mechanisms of secondary damage in spinal cord injury: effect of potassium. J Neurotrauma 10:349-362.

Lutz PL (1992) Mechanisms for anoxic survival in the vertebrate brain. Annu Rev Physiol 54:601-618.

Lutz PL, Edwards R, McMahon PM (1985) $\gamma$-aminobutyric acid concentrations are maintained in anoxic turtle brain. Am J Physiol 249: R372-R374.

Meiri H, Gross B (1989) Modification of the Na-dependent action potential in myelinated fibers of rat sciatic nerve exposed to phorbol ester. Brain Res 502:401-409.

Mené P, Pugliese F, Cinotti GA (1991) Regulation of $\mathrm{Na}^{+} / \mathrm{Ca}^{2+}$ exchange in cultured human mesangial cells. Am J Physiol 261:F466F473.

Morris ME; Di Costanzo GA, Fox S, Werman R (1983a) Depolarizing action of GABA on myelinated fibers of peripheral nerve. Brain Res 278:117-126.

Morris ME, Di Costanzo GA, Barolet A, Sheridan PJ (1983b) Role of $\mathrm{K}^{+}$in $\mathrm{GABA}$-evoked depolarization of peripheral nerve. Brain Res 278:127-135.

Mosinger JL, Yazulla S, Studholme KM (1986) GABA-like immunoreactivity in the vertebrate retina: a species comparison. Exp Eye Res 42:631-644.

Nakadate T, Yamamoto S, Aizu E, Nishikawa K, Kato R (1990) H7 , a protein kinase $C$ inhibitor, inhibits phorbol ester-caused ornithine decarboxylase induction but fails to inhibit phorbol ester-caused suppression of epidermal growth factor binding in primary cultured mouse epidermal cells. Mol Pharmacol 36:917-924.

Nilsson GE, Lutz PL (1991) Release of inhibitory neurotransmitters in response to anoxia in turtle brain. Am J Physiol 261:R32-R37.

Nilsson GE, Alfaro AA, Lutz PL (1990) Changes in turtle brain neurotransmitters and related substances during anoxia. Am J Physiol 259:R376-R384.

Ochi S, Lim JY, Rand MN, During MT, Sakatani K, Kocsis JD (1993) Transient presence of GABA in astrocytes of the developing optic nerve. Glia 9:188-198.

Radian R, Ottersen OP, Storm Mathisen J, Castel M, Kanner BI (1990) Immunocytochemical localization of the GABA transporter in rat brain. J Neurosci 10:1319-1330.

Ransom BR, Philbin DM (1993) Anoxia-induced extracellular ionic changes in CNS white matter: the role of glial cells. Can J Physiol Pharmacol 70:S181-S189.

Ransom BR, Yamate CL, Connors BW (1985) Activity-dependent shrinkage of extracellular space in rat optic nerve: a developmental study. J Neurosci 5:532-535.

Ransom BR, Watz W, Davies PK, Carlini WG (1992) Anoxia-induced changes in extracellular $\mathrm{K}^{+}$and $\mathrm{pH}$ in mammalian central white matter. J Cereb Blood Flow Metab 12:593-602.

Sabers A, Gram L (1992) Pharmacology of vigabatrin. Pharmacol Toxicol 70:237-243.

Sakatani K, Hassan AZ, Chesler M (1991a) GABA-sensitivity of dorsal column axons: an in vitro comparison between adult and neonatal rat spinal cords. Dev Brain Res 61:139-142.

Sakatani K, Hassan AZ, Ching W (1991b) Age-dependent extrasyn- aptic modulation of axonal conduction by exogenous and endogenous GABA in the rat optic nerve. Exp Neurol 114:307-314.

Sakatani K, Black JL, Kocsis JD (1992) Transient presence and functional interaction of endogenous GABA and GABA-A receptors in developing rat optic nerve. Proc R Soc Lond [Biol] 247:155-161.

Schmalzing G, Eckard P, Kroner S, Passow H (1990) Down-regulation of surface sodium pumps by endocytosis during meiotic maturation of Xenopus laevis oocytes. Am J Physiol 258:C179-C184.

Shimada N, Graf R, Rosner G, Heiss WD (1993) Ischemia-induced accumulation of extracellular amino acids in cerebral cortex, white matter, and cerebrospinal fluid. J Neurochem 60:66-71.

Siemers ER, Rea MA, Felten DL, Aprison MH (1982) Distribution and uptake of glycine, glutamate and g-aminobutyric acid in the vagal nuclei and eight other regions of the rat medulla oblongata. Neurochem Res 7:455-468.

Simmonds MA (1983) Depolarizing responses to glycine, $\beta$-alanine and muscimol in isolated optic nerve and cuneate nucleus. $\mathrm{Br} \mathrm{J}$ Pharmacol 79:799-806.

Stys PK, Ransom BR, Waxman SG (1990) Role of extracellular calcium in anoxic injury of mammalian central white matter. Proc Natl Acad Sci USA 87:4212-4216.

Stys PK, Ransom BR, Waxman SG (1991) Compound action potential of nerve recorded by suction electrode: a theoretical and experimental analysis. Brain Res 546:18-32.

Stys PK, Waxman SG, Ransom BR (1992) Ionic mechanisms of anoxic injury in mammalian CNS white matter: role of $\mathrm{Na}^{+}$channels and $\mathrm{Na}{ }^{-}-\mathrm{Ca}^{2}+$ exchanger. J Neurosci 12:430-439.

Stys PK, Sontheimer H, Ransom BR, Waxman S (1993) Noninactivating, tetrodotoxin-sensitive $\mathrm{Na}^{+}$conductance in rat optic nerve axons. Proc Natl Acad Sci USA 90:6976-6980.

Tamaoki T, Nomoto H, Takahashi I, Kato Y, Morimoto M, Tomita F (1986) Staurosporine, a potent inhibitor of phospholipid/ $\mathrm{Ca}^{2+} \mathrm{de}-$ pendent protein kinase. Biochem Biophys Res Commun 135:397402.

Todd AT, Sullivan AC (1990) Light microscope study of the coexistence of GABA-like and glycine-like immunoreactivities in the spinal cord of the rat. J Comp Neurol 296:496-505.

Ui M (1984) Islet-activating protein, pertussis toxin: a probe for function of the inhibitory guanine nucleotide regulatory component of adenylate cyclase. Trends Pharmacol Sci 5:277-279.

Van De Hayden JAM, De Kloet ER, Versteeg DHL (1979) GABA content of discrete brain nuclei and spinal cord of the rat. $J$ Neurochem 33:857-861.

Vasilets LA, Schmalzing G, Madefessel K, Haase W, Schwarz W (1990) Activation of protein kinase $C$ by phorbol ester induces downregulation of the $\mathrm{Na}^{+} / \mathrm{K}^{+}-\mathrm{ATPase}$ in oocytes of Xenopus laevis. J Membr Biol 118:131-142.

Waxman SG, Black JA, Stys PK, Ransom BR (1992) Ultrastructural concomitants of anoxic injury and early post-anoxic recovery in rat optic nerve. Brain Res 574:105-119.

Waxman SG, Black JA, Ransom BR, Stys PK (1993) Protection of the axonal cytoskeleton in anoxic optic nerve by decreased extracellular calcium. Brain Res 614:137-145.

West JW, Numann R, Murphy BJ, Scheuer T, Catterall WA (1991) A phosphorylation site in the $\mathrm{Na}^{+}$channel required for modulation by protein kinasc C. Science 254:866-868.

Wijesinghe RS, Geilen FLH, Wikswo JP Jr (1991) A model for compound action potentiais and currents in a nerve bundle. I. The forward calculation. Ann Biomed Eng 19:43-72. 